\title{
FIFTY YEARS OF PROGRESS IN ICE PHYSICS
}

\author{
By JOHN W. GLEN \\ (Department of Physics, University of Birmingham, Birmingham B15 2TT, England)
}

\begin{abstract}
Our understanding of the basic physics underlying the properties of ice has dramatically changed during the last half century. At the beginning of this period it was known that the water molecules in ice were arranged with tetrahedral hydrogen bonding, and it had just been established that the hydrogens were not crystallographically arranged on these bonds; however, the way in which water molecules could re-orient was unknown and the implications of this for the mechanical properties and hence for glacier flow were unexplored. The suggestion of electrical point defects in ice, the $L$ and $D$ defects of Bjerrum and the ionic defects, pointed the way to an understanding first of the dielectric relaxation and electrical conductivity of ice and then to a possible interaction between these electrical properties and the movement of dislocations, and hence the plastic deformation of ice.

Menwhile, much work was done to study the behaviour of ice under various physical conditions and to establish more rigorous laws for many physical properties of single crystals of ice and of various forms of polycrystalline ice, and much work was done to find the crystallographic structures of the various phases of ice including those already known to exist at high pressures. The intriguing appearance of a cubic form of ice at low temperatures was also investigated together with vitreous ice formed at even lower temperatures.

Many of these properties are of great interest to meteorologists trying to understand cloud physics and the physics of thunderstorm electricity as well as to astronomers thinking about ice in space, comets, the icy satellites of the planets, or even on the planets themselves.
\end{abstract}

ICE physics and its development over the last half century is not easy to tackle in 45 minutes. In 1974, Peter Hobbs published a book with the title Ice physics that had 835 pages. Most of the work he summarized was done in the period under review. Ice physicists have got together at conferences at various times. The first, at Erlenbach in Switzerland in 1962 was quite a small affair. Another, in Sapporo in 1966 (Ōura, 1967), covered more applied aspects. Munich in 1968 (Riehl and others, 1969) was followed by the institution of an informal international committee which has arranged for further conferences in Ottawa in 1972 (Whalley and others, 1973), Cambridge in 1977 (Glen and others, 1978), Rolla in 1982 (El-Sayed, 1983), and Grenoble in 1986. The last in this series occurred last week [September 1986] and will be published in 1987 in Journal de Physique Colloques. Each of these conferences has had many papers over a wide range of ice physics and the volumes resulting from them give an impressive overview of the amount of work which has been done - and the impossibility of summarizing it properly in this lecture. Thus, what I include will be largely a subjective view of what seem to be the most interesting developments in ice physics - in our basic understanding of the physics underlying the behaviour of our material, ice, which is the link between all the geophysical phenomena discussed in the other lectures.

Ice is a very interesting and important material, not only to the glaciologist but also to meteorologists and geologists, physicists and chemists, astronomers and biologists. The physical properties of ice are interesting and unusual, and are responsible for behaviour that has allowed life to develop on Earth - the unusual (but not unique) situation where the solid is less dense than the liquid allows water bodies to survive under an insulating cover of ice and so preserve the marine life underneath. This, of course, is one physical property of ice that has been known for a very long time, but another very important peculiarity of ice had only just been appreciated 50 years ago at the time the International Glaciological Society was founded, and much of the most interesting ice physics has come from studying the consequences. This is the strange situation of the locations of the hydrogen atoms in ice.

One of the first applications of X-ray crystallography was to determine the structure of ice. In 1921, Bragg (1921) interpreted measurements by Dennison (1921) to show that the oxygen atoms were arranged tetrahedrally to form the hexagonal structure we call ice Ih. However, X-rays do not readily locate very light atoms, and the position of the hydrogens is not indicated by the experimental data. Bragg supposed they were half-way between the oxygen atoms, but Bernal and Fowler (1933) suggested, more plausibly, that two hydrogens were near to each oxygen atom so that every bond had one hydrogen on it and every oxygen had two hydrogens near it, so that water molecules are preserved in the structure. In this model each water molecule is essentially a nearly spherical object with the hydrogen nuclei, two to each molecule, being small centres of positive charge (protons) partly compensated by concentrations of electron distribution, while two other concentrations of electron distribution give two centres of negative charge. In the structure the positive centres of one water molecule are electrostatically attracted to the negative centres of the neighbouring water molecules. To account for the fact that ice is not observed to be polar in its properties, a very large unit cell would be needed if the hydrogens were to be regularly arranged, but thermal measurements suggested that ice Ih had some built-in disorder, and Pauling (1935) suggested that this might be due to the hydrogen atoms being disordered; in other words, if we know where one hydrogen atom is, we do not automatically know where corresponding hydrogens are in a neighbouring, crystallographically equivalent part of the ice structure - ice is a crystal as regards the oxygens but a glass as regards the hydrogens (Fig. 1).

This, then, was the understanding of the basic physics of ice that had been achieved 50 years ago, but the way in which this unusual feature of random hydrogen positions was related to the macroscopic properties of ice was still to be worked out. The problem can perhaps best be understood by considering what happens when ice is put in an electric field. In fact, in such an experiment the ice becomes polarized and the dipole moment per water molecule produced is of the same order of magnitude as it is for liquid water. Now, this is really a very surprising result. In liquid water it is obvious that individual water molecules, which, as we have seen, have centres of positive and negative charge within them, can be expected to rotate in such a way that the energy of the dipole is lowered - they align themselves with the electric field. Since ice produces about the same dipole moment, this means that in ice, too, water molecules align themselves with the field - but how can they do this? Even if the hydrogens are random, any individual water molecule has four neighbours, two of 


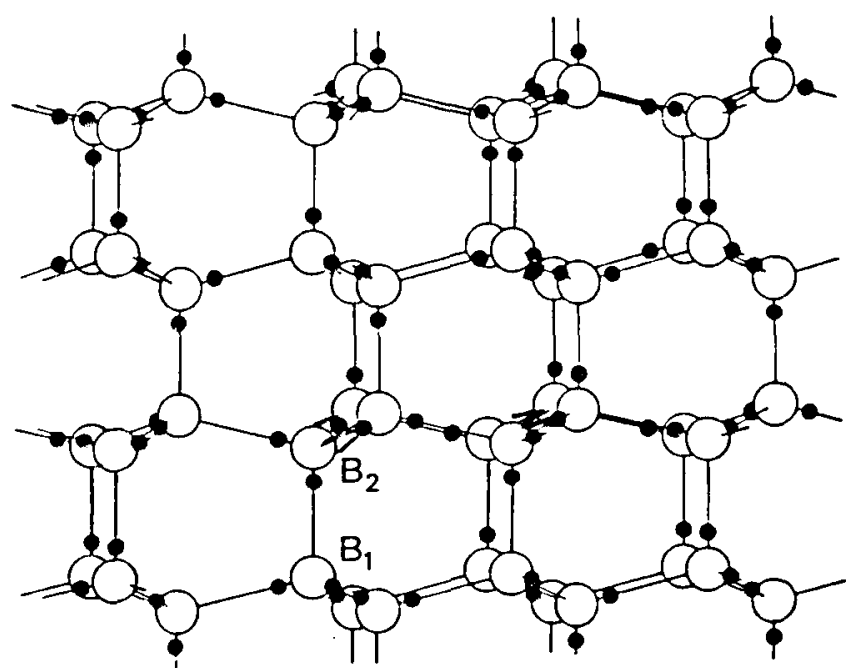

Fig. 1. The arrangement of water molecules in ice Ih. Note that the three water molecules bonded to $B_{2}$ are vertically above those bonded to $B_{1}$. The hydrogen atoms are shown in positions consistent with the Bernal-Fowler rules.

which present negative charges to it and two of which present positive charges, so the orientation of the water molecule is completely determined and it cannot turn round unless its neighbours turn as well. Indeed, if the Bernal and Fowler structure with Pauling's randomness were the whole story, ice ought to be much less polarizable than water.

The solution was found by Bjerrum (1951), who suggested that the two rules for the structure suggested by Bernal and Fowler (1933) (and now known as the BernalFowler rules) may occasionally be breached and that the defects resulting from breaching these rules allow ice molecules to re-orient. One of the rules states that each oxygen has two hydrogens, that is to say we are dealing with water molecules. Now, it is well known that in water this rule is occasionally breached - water is weakly ionized and according to the chemical law of mass action has in equilibrium a small number of $\mathrm{H}_{3} \mathrm{O}^{+}$and $\mathrm{OH}^{-}$ions

$$
2 \mathrm{H}_{2} \mathrm{O} \rightleftharpoons \mathrm{H}_{3} \mathrm{O}^{+}+\mathrm{OH}^{-} \text {. }
$$

It is this small number of ions that allows water to conduct electricity and their number is assessed in logarithmic form by the so-called $\mathrm{pH}$. Thus, it is surely to be expected that in ice too a very small number of oxygens will have three or one hydrogen instead of two. Now, if this is so, Bjerrum pointed out that hydrogen atoms could move from one molecule to another (Fig. $2 a$ and $b$ ) - if one of the three hydrogens of an $\mathrm{H}_{3} \mathrm{O}^{+}$ion moves along its bond to the neighbouring molecule, then that molecule becomes the ion. If now another hydrogen of the new molecule moves away, a third molecule has become the ion and the molecule through which the ion has passed has been reoriented. Thus, a mechanism is found for re-orienting water molecules, and it would work equally well for an $\mathrm{OH}^{-}$ion. Note that, unlike the case in water, the oxygens have not moved at all, the charge movement is entirely due to protons (hydrogen nuclei) moving along bonds.

The second Bernal-Fowler rule states that there is one hydrogen per bond. If we now suppose that this too is breached for a small number of bonds, we get other sorts of point defect, now known as Bjerrum defects. A bond with no hydrogens on it is called an L-defect (from the Danish word leer for empty), one with two hydrogens is called a D-defect (doppelt or double).

Just as in the case of ionic defects, the Bjerrum defects can move through the structure and cause water molecules to rotate (Fig. $2 \mathrm{c}$ and $\mathrm{d}$ ), only this time the process is one in which protons (hydrogen nuclei) move from one bond to another on the same water molecule. In this case, it is even more obvious that the water molecule is rotated by the process.

In fact, any one sort of defect could cause ice to
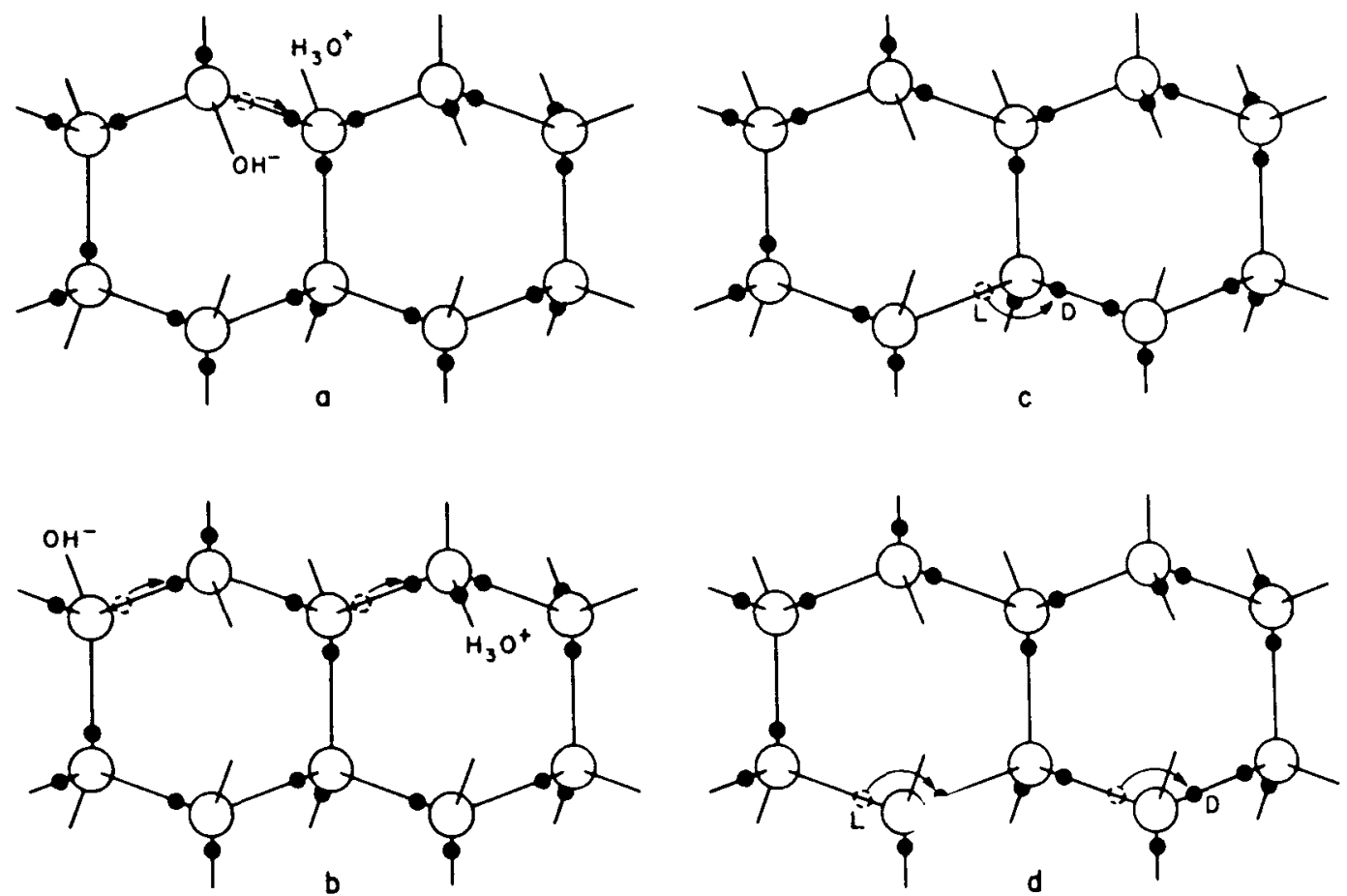

Fig. 2. The creation and movement of electrical point defects in ice. In (a) the movement of a proton from the position shown with a dashed circle creates a positive and a negative ion, and $(b)$ shows how movements of a proton along a bond can make the ions migrate. (c) shows how the movement of a proton around an oxygen atom can create an L-defect and a D-defect, and (d) shows how this defect can also migrate by further movements of protons around oxygen atoms. The movement of the prolons is to the right in all cases, but the movement of ions in (b) leaves the water molecules oriented with their protons to the left, while the movement of $L$ - and D-defects in (d) leaves them with their protons to the right. 
polarize in an electric field, while if both ions and Bjerrum defects are present, protons can move large distances in the ice; in other words, ice can conduct a direct current. They move along a bond by the passage of an ionic defect and from one bond to another by the passage of a Bjerrum defect. In this way, Bjerrum's ideas can explain both the dipole moment (i.e. the dielectric permittivity) of ice and also the small d.c. conductivity of ice.

The full implications of this for the electrical properties of ice have been the subject of much experiment and theory throughout the half century we are considering. The possibility of using ice doped with HF was exploited first by the Zürich group under Gränicher, and the resulting theory was developed by Jaccard $(1959,1964)$ and refined by Hubmann (1979). Experiments are not particularly easy to perform, especially when the d.c. conductivity is to be studied, because the current is being carried by protons whereas most electrical circuits consist of conductors for electrons, so that space charges can build up in the ice and prevent proper measurements unless special contacts exist (protodes!) which will give out or receive protons. Work to develop such contacts was done by the group in Grenoble using ion-exchange membranes (Kahane, 1969) and ionized hydrogen gas (Auvert and Kahane, 1973),
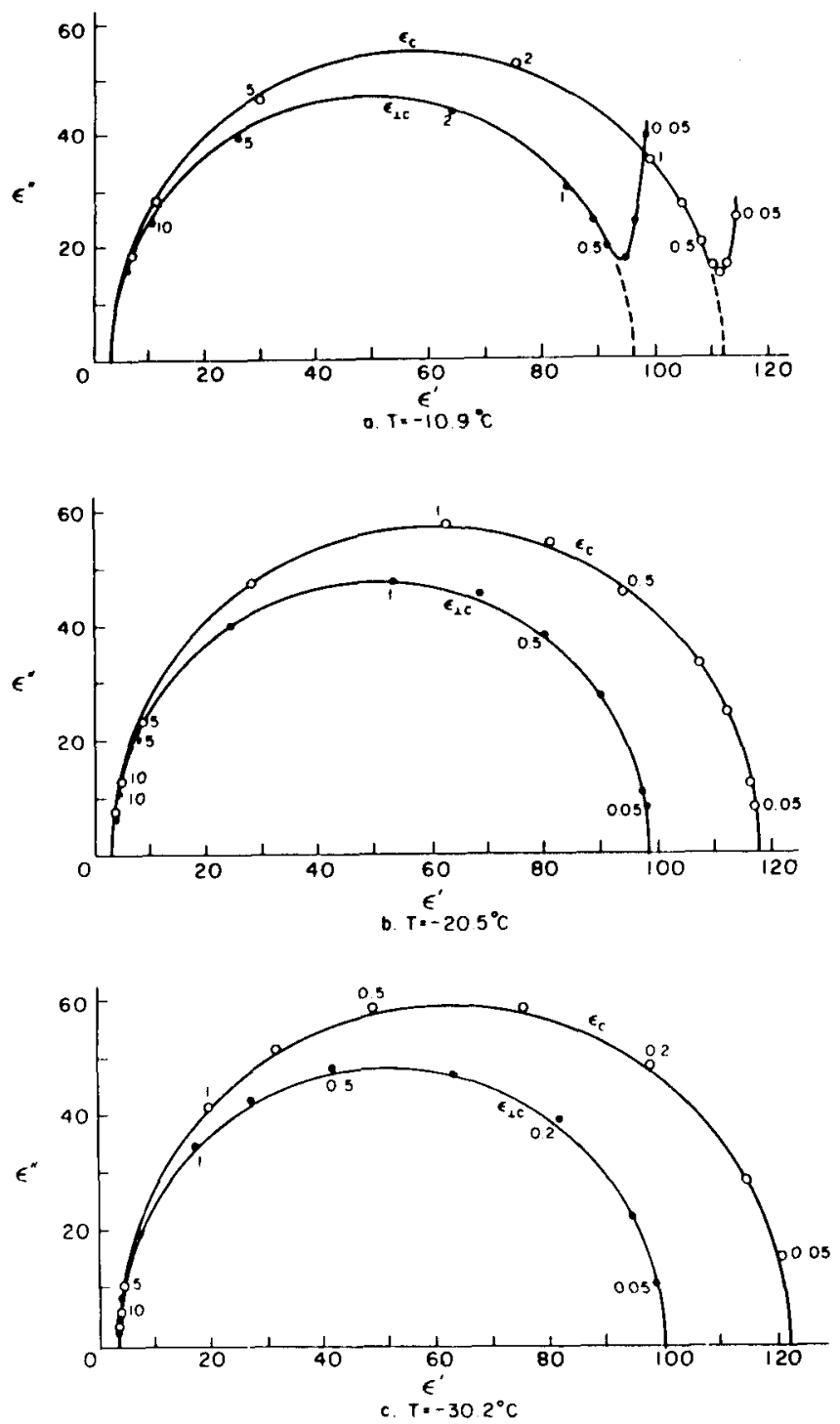

Fig. 3. Plot of the real and imaginary parts of the permittivity of ice (the so-called Cole-Cole plot). The three plots are for different temperatures as marked; the two curves on each plot are for measurements parallel and perpendicular to the c-axis. The plots are almost perfect semi-circles. The deviations at the right of the top plot are due to the effect of electrical conductivity. The frequencies in $\mathrm{kHz}$ are marked against points. (After Humbel and others, 1953.) and also by the group in Munich using hydrogen-loaded palladium (Engelhardt and Riehl, 1965, 1966). This latter technique was further refined by Petrenko during a sabbatical visit to Birmingham (Petrenko and others, 1983) and has been used by him to inject protons into ice and study space-charge limited currents. These experiments have served to provide experimental values for the energies required to produce and move the different kinds of defects, and to give a reasonable theoretical background for understanding the electrical properties of ice.

These properties are of great importance for understanding not only the behaviour of ice in a static electric field such as is used in resistivity sounding of glaciers, but also in alternating fields including those provided by electromagnetic waves. As the frequency increases, so the ability of water molecules to rotate decreases and a typical relaxation process occurs (Fig. 3). This was first studied in detail for polycrystalline ice by Auty and Cole (1952), who showed that pure ice is really a very good example of a relaxation process in a dielectric. At the higher frequencies used in radio echo-sounding, ice has very little absorption; that is to say, the dipole polarization is essentially in phase with the applied field, but the existence of reflection horizons implies relatively sudden changes in the dielectric permittivity of the ice that have puzzled glaciologists since their discovery. The electrical properties are also of much interest to cloud physicists, since ideas of the origin of thunderstorm electricity are related to various electrical phenomena of ice crystals.

The disorder of the hydrogen atoms in ice also poses problems for understanding the mechanical properties of ice. Early experiments had shown that ice single crystals deform easily only by slip on the (0001) or basal planes and consequently polycrystalline ice is much harder to deform than single crystals. The physical explanation of ice deformation had thus first to understand why ice deforms easily only on the basal plane and to discover what limits the deformation on that plane, and then had to see how crystals of different orientation interact to produce the creep properties (flow law) of polycrystalline ice. Experiments by the present author had established (Glen and Perutz, 1954) that single crystals have accelerating creep curves (Fig. 4), while (Glen, 1955) polycrystalline ice had decelerating creep curves (Fig. 5) whose steady-state creep was related to stress by a power law. Since ice is crystalline, we would expect these properties to result from the ability of dislocations to move through the ice, impeded either by the force required to make the dislocations move at all or by the force of interaction between dislocations. However, the same disorder of the hydrogen atoms introduces a major difficulty here since, when a crystal deforms by movement of dislocations, the molecules break a bond with one partner and remake it with another. If one of these molecules has a hydrogen at the top of a bond, it can only remake the bond with a molecule so oriented as to have no hydrogen at the bottom of the bond, and with randomized bond orientations this

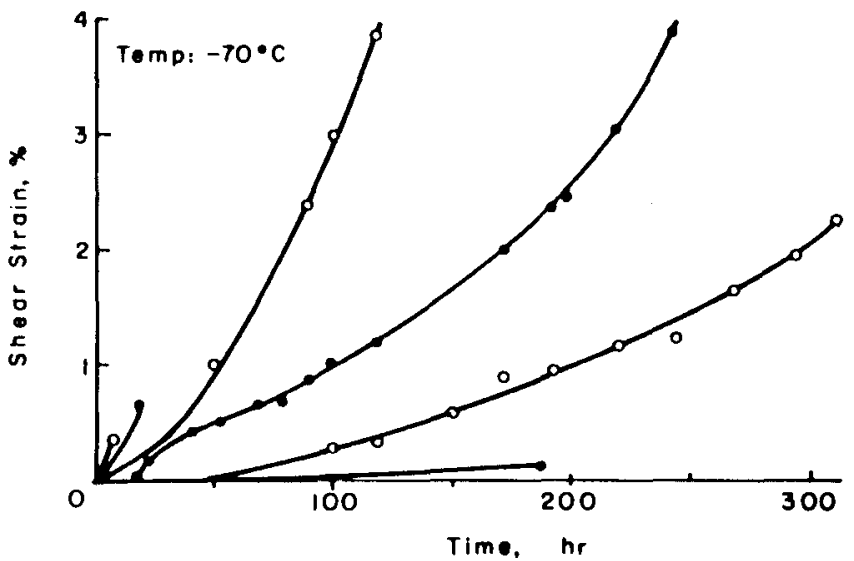

Fig. 4. Creep curves of ice single crystals deformed under various stresses at $\rightarrow 70^{\circ} \mathrm{C}$. (After Jones and Glen, 1969.) 


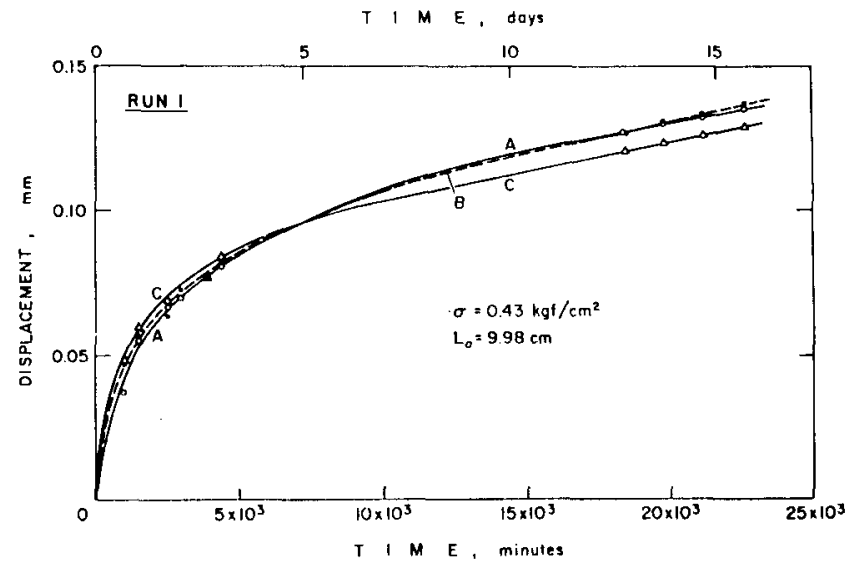

Fig. 5. Low-stress creep curves for fine-grained ice whose crystal orientation was initially random. Test temperature $-2.06^{\circ} \mathrm{C}$. Constant axial compressive stress of 0.42 bar on ice which had not been previously loaded. (After Mellor and Testa, 1969.)

will frequently not be the case (Glen, 1968) (Fig. 6). Thus, there is a problem about dislocation movement in ice that is peculiar to a material with this kind of randomness, and there is therefore great interest in measuring the velocity with which dislocations move through ice and comparing the results with theories, and also for seeing whether dislocations can in fact move on non-basal planes. A good method for achieving this is to use $\mathrm{X}$-ray topography which in principle allows us to see dislocations in ice. The first successful use of this technique in ice was reported by Hayes and Webb (1965) and it has been used by groups in Sapporo (Fukuda and Higashi, 1969, 1973) and Villeurbanne (Mai, 1976) to deduce dislocation velocities. The observed velocities are such that it is difficult to account for them theoretically on a model in which bonds have to be re-oriented by the mechanisms discussed above (Whitworth, 1978, 1983). In Birmingham, we are currently doing experiments using the synchrotron radiation source so that exposure times for $\mathrm{X}$-ray topographs are much reduced and more direct dynamical experiments are possible.

The effect of the different orientations of single crystals on a polycrystalline aggregate and the difference in flow rate to be expected for ice with different preferred orientations were considered by Lile (1978), although a detailed study based on the non-basal mechanisms, and grain-boundary migration and sliding, has not been attempted because of the continuing lack of basic information on these processes.

Fifty years ago only the structure of ice Ih was known; however, it was known from the work of Tammann (1900) that at high pressures and various temperatures ice could be converted into one of two denser phases, and that these denser phases could be retained at low pressure if they were held at liquid-air temperatures. This work was extended by Bridgman (1935) who found two further phases of $\mathrm{H}_{2} \mathrm{O}$ ice and one additional phase for $\mathrm{D}_{2} \mathrm{O}$ ice, and later (Bridgman, 1937) extended his work to still higher pressures, obtaining yet another phase (Fig. 7). Bridgman noticed that the boundary line on the phase diagram between ice VI and VII appeared to change the angle it makes with the temperature axis near $0^{\circ} \mathrm{C}$ and this, and the similar divergence of the boundaries of ice II, suggest that these phases have lower entropy than their neighbours. Whalley and others (1968) suggested that this means the phases have proton ordering (the ordered form of ice VII they called ice VIII), and this has subsequently been confirmed by other measurements. Similarly, Whalley's group identified a proton-ordered form of ice III that they called ice IX. Much work was done by this group and also by Kamb (Kamb and Datta, 1960; Kamb, 1964, 1965; Kamb and Davis, 1964; Kamb and others, 1967; Hamilton and others, 1969; Engelhardt and Kamb, 1978) to find the crystal structures of these high-pressure ices and some of these are shown in Figures 8-12. All of them have hydrogen bonds similar to those in ice Ih with four
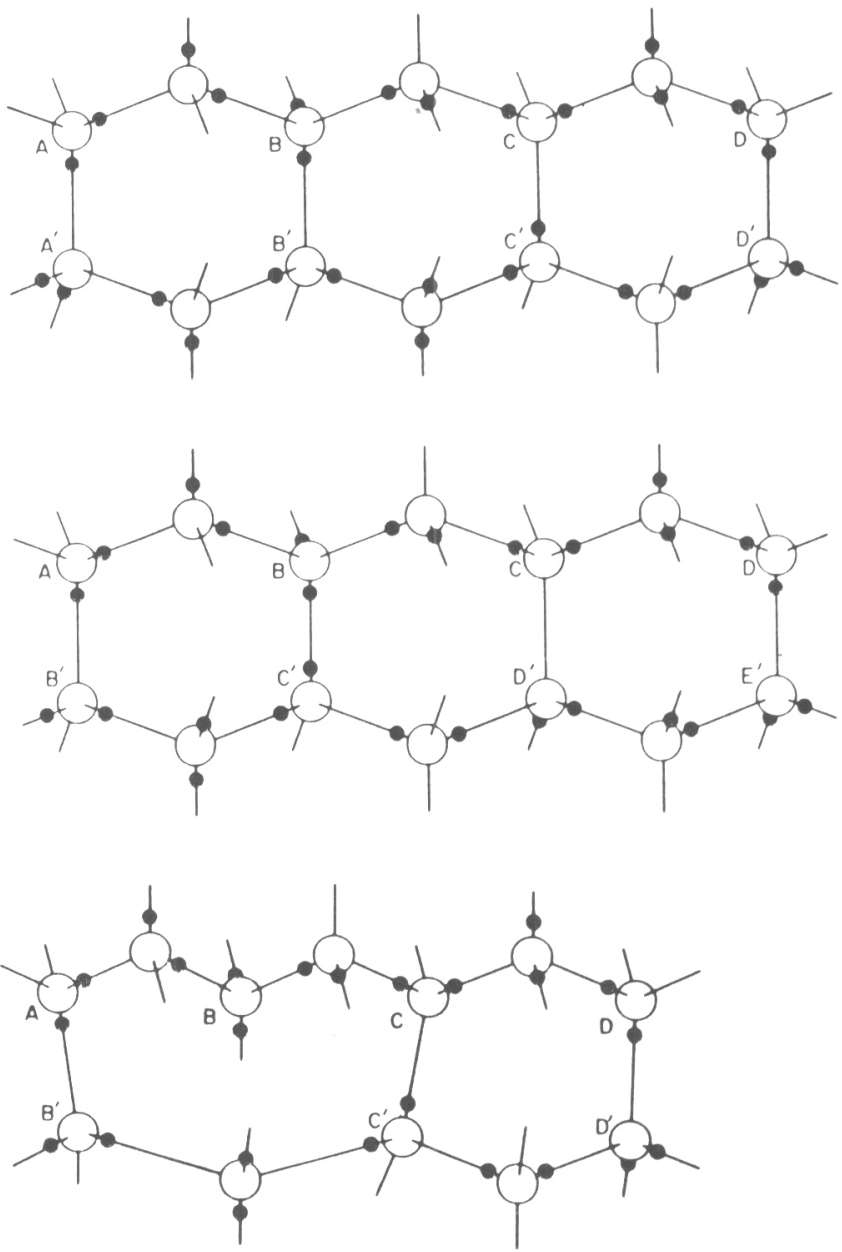

Fig. 6. The effect of moving a dislocation through the ice Ih structure. The top diagram shows a part of the structure with the protons (black circles) at random consistent with the Bernal-Fowler rules. The middle diagram shows the same structure after the top has sheared to the right relative to the bottom by the passage of a dislocation. Note that this has introduced $L$ - and $D$-defects. An intermediate stage between these two conditions is shown in the bottom diagram where the dislocation is at a position where it has already moved atom $A$ to join $B^{\prime}$. Atom $B$ has a dangling bond and. for the dislocation to move on, it must link to $C^{\prime}$. However, it already has a proton on its bond, and to avoid making a D-defect the proton above $C^{\prime}$ must move away, e.g. to the other end of its bond by the passage of $a$ mobile ion, or around $C$ by the passage of a mobile $L$-defect.

molecules bonded to each water molecule, but with different angles and different numbers of molecules in the rings. At the highest pressures, ices VI, VII, and VIII are interesting structures. In order to get the necessary density with only four bonded neighbours, the structures consist of two interpenetrating parts. In the case of ice VII (and VIII) these are both simple structures similar to ice Ih but with the face-centred cubic symmetry of diamond or germanium. Finally, it has been hypothesized that at even higher pressures the hydrogen bonds would eventually get so squashed that ice would have the hydrogen in the middle of the bond - ice $X$ (Hirsch and Holzapfel, 1986).

The cubic arrangement that appears in ice VII is also sometimes observed as a simple structure, (not interpenetrating) at low pressures. When ice is formed from the vapour at around $-120^{\circ} \mathrm{C}$ or when high-pressure ices transform as they are warmed up, then this ice, known as ice Ic, is formed. This was first observed by König (1943). At still lower temperatures ice is deposited in vitreous or amorphous form. This also transforms to ice Ic when 


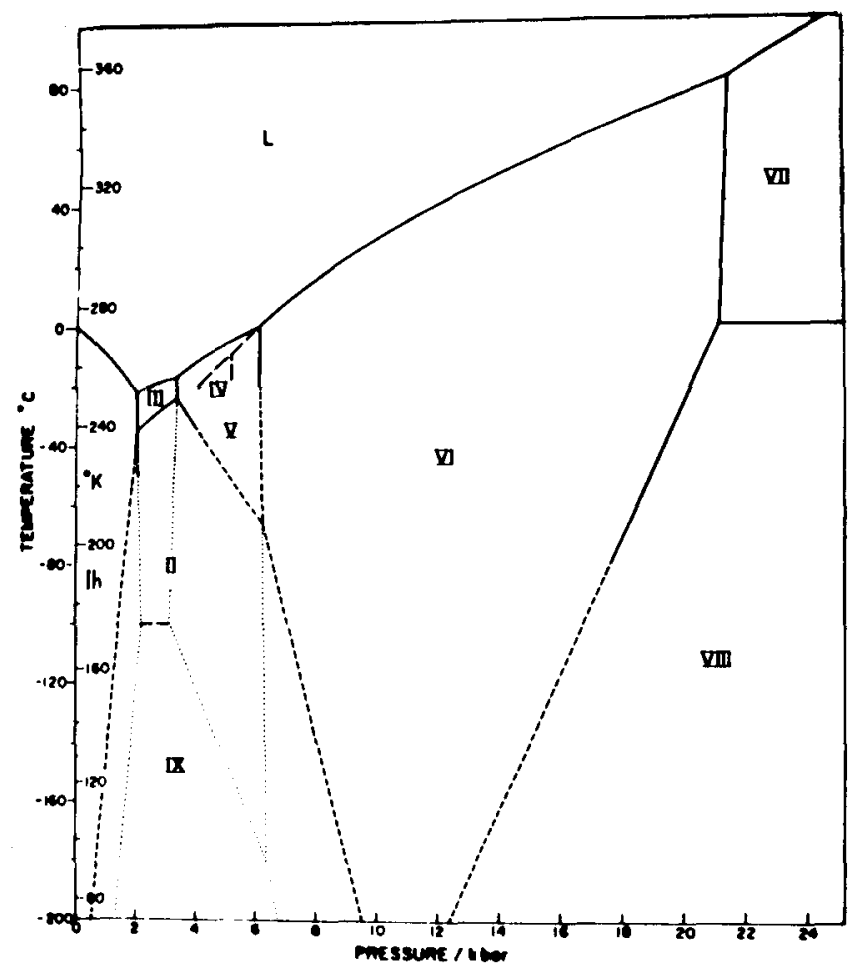

Fig. 7. Phase diagram of ice. Dashed lines are extrapolated or calculated boundaries. Metastable phases (apart from ice IV and Ic) are shown by light lines. (After Whallev and others, 1968.)
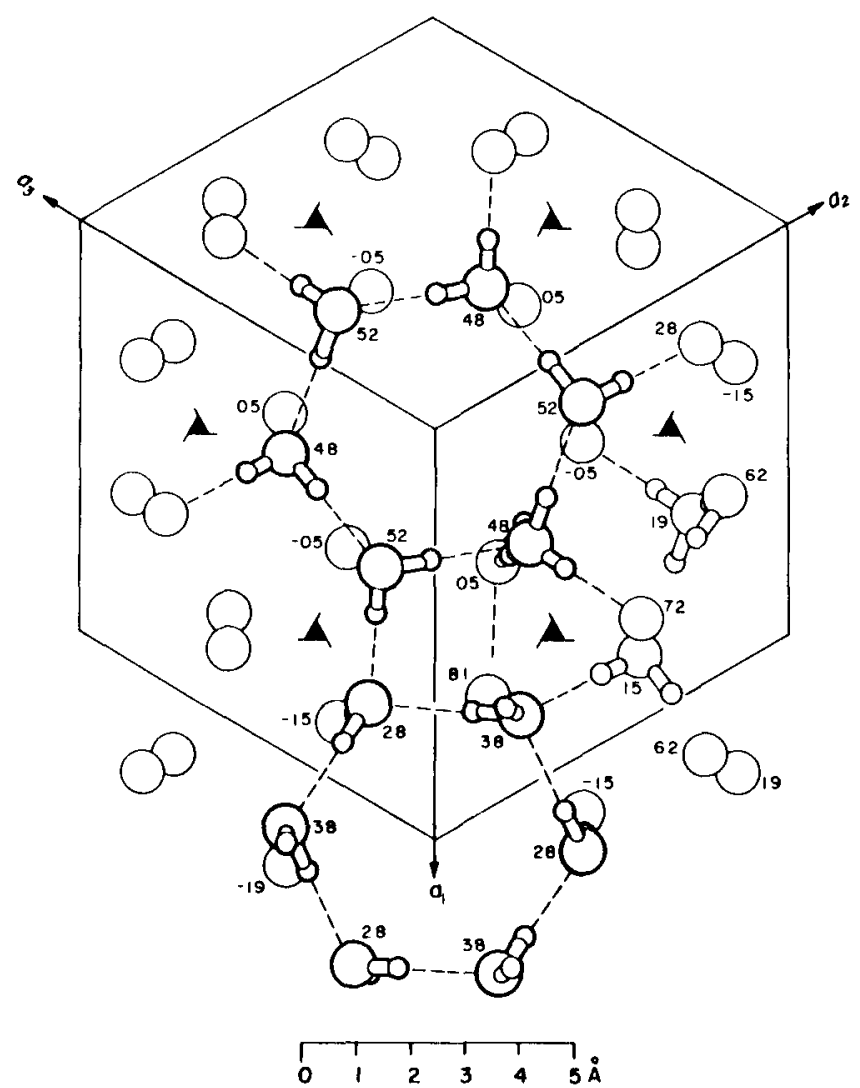

Fig. 8. The structure of ice II. The heights of atoms above a hexagonal plane are given in hundredths of the $c$ dimension of the unit cell. One six-ring of each type is emphasized. Note that in the top ring the protons are anti-clockwise from the oxygen atoms and radial, whereas in the lower they are anti-clockwise and alternately up and down. (After Kamb, 1964.)

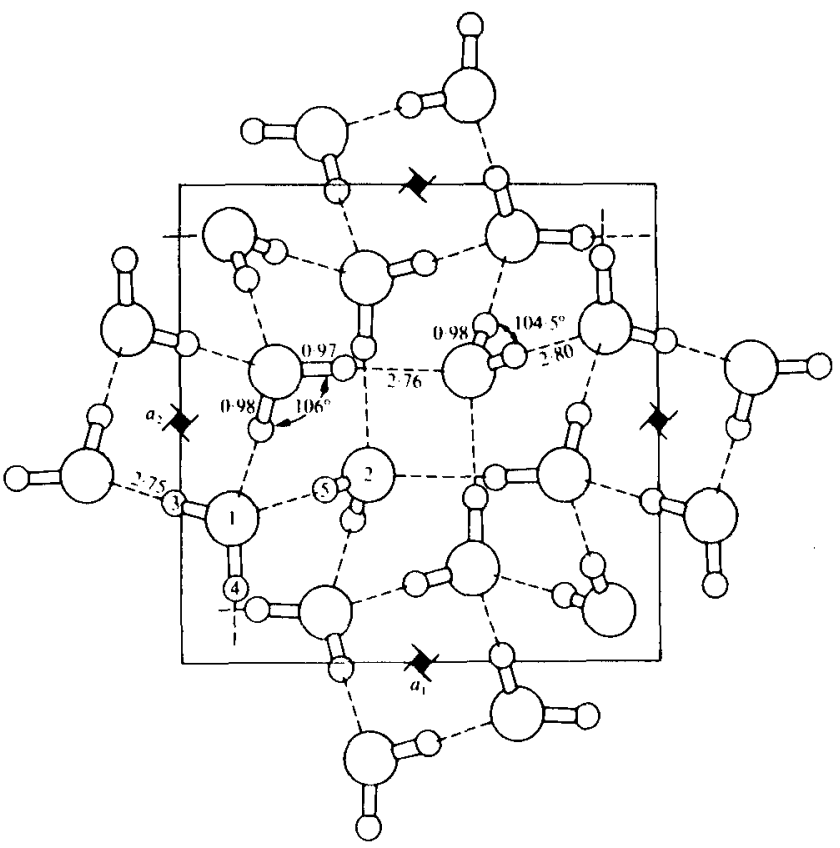

Fig. 9. Structure of ice $I X$, viewed along the tetragonal c-axis. Lengths are in $\dot{A}$. Water molecules of type 1 form helical chains around the $4_{1}$-axes parallel to the c-axis. These helices are linked together laterally by molecules of type 2. If the protons were disordered, the structure would be ice III. (After Hamilton and others, 1969.)

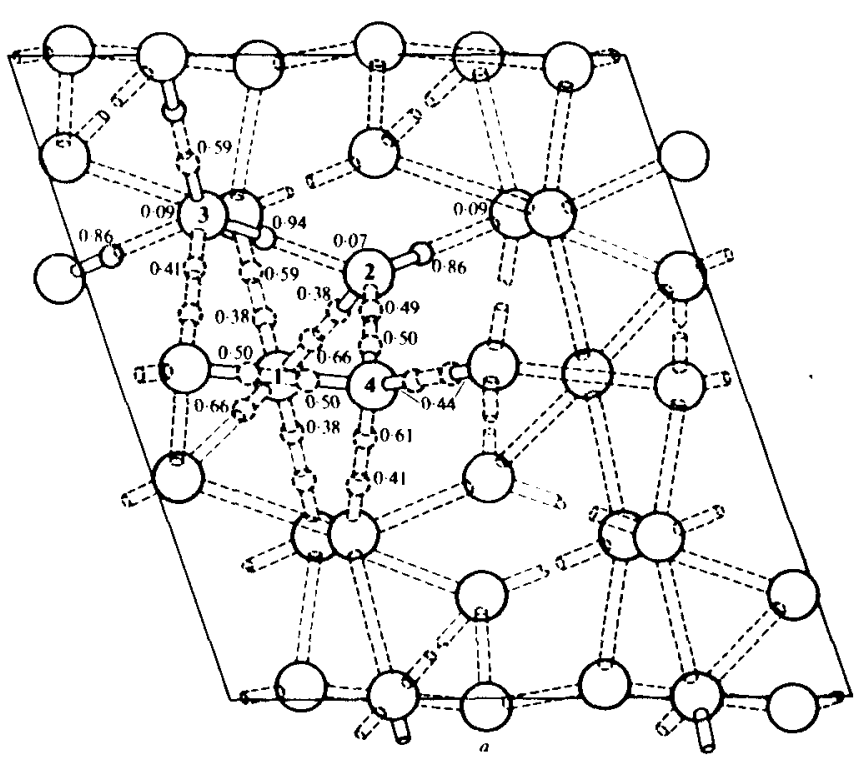

Fig. 10. Structure of ice $V$ at $110 \mathrm{~K}$, viewed along the monoclinic $b$-axis. Oxygen atoms are shown as large circles. Lengths are in $\dot{A}$. Some of the deuteron positions are indicated by small circles, accompanied by the corresponding probability factor. The nearly full deuterons are shown solid, the approximately half deuterons are dashed, and the nearly absent deuterons are not drawn. The dotted rods are the hydrogen bonds. The details of bond lengths and angles are omitted. (After Hamilton and others, 1969.)

heated. It seems doubtful however whether ice Ic is ever the stable form of ice.

Knowing the arrangement of water molecules in ice is one aspect of an understanding of ice crystals, knowledge of the way in which ice crystals develop in Nature is another to which very much effort has been devoted over 

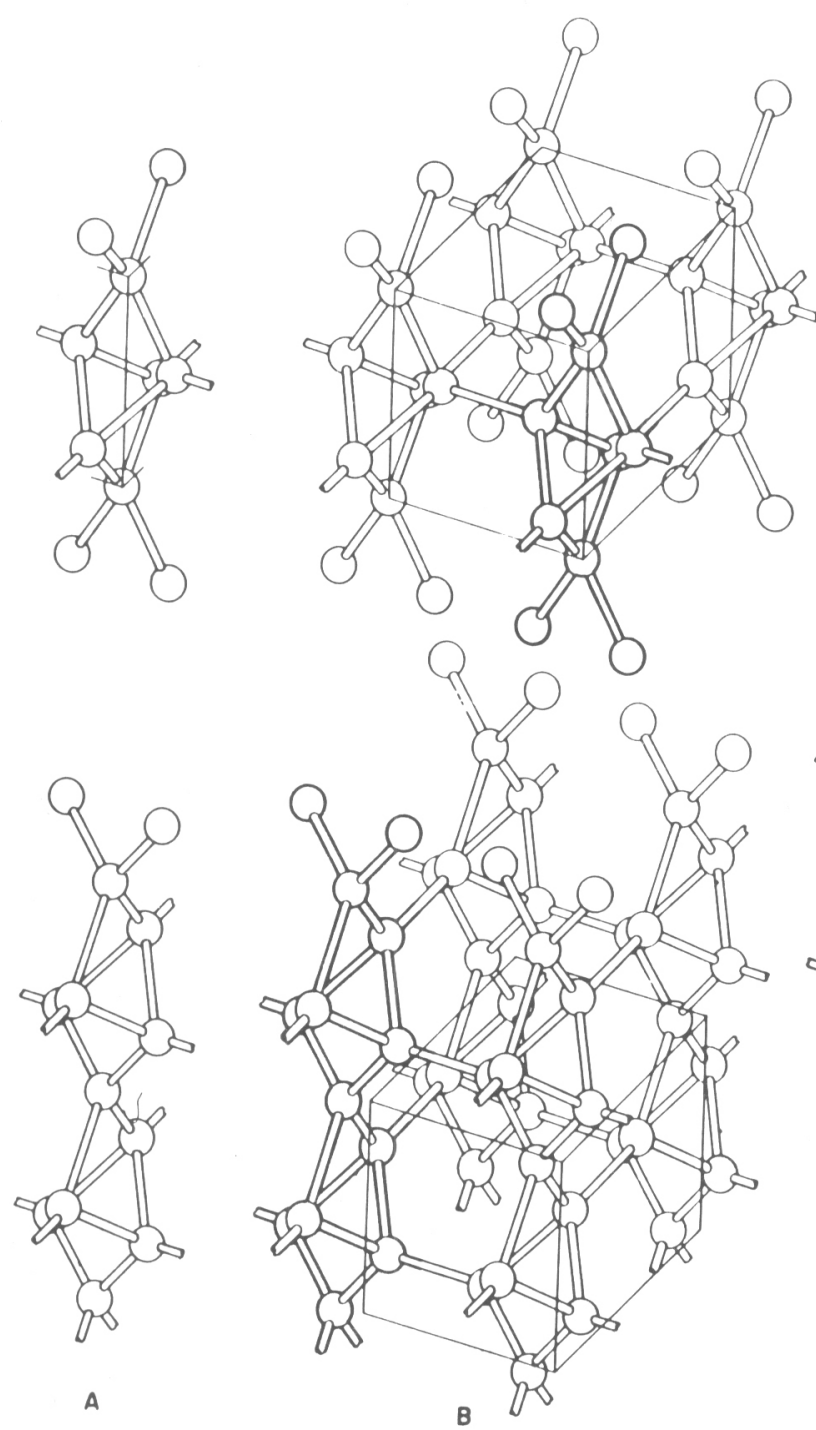

Glen: Ice physics

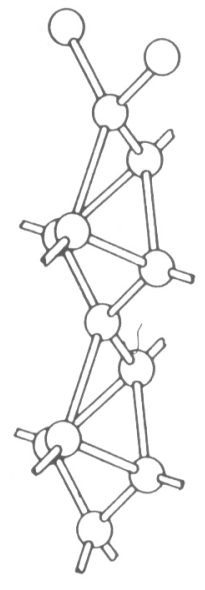

A

B

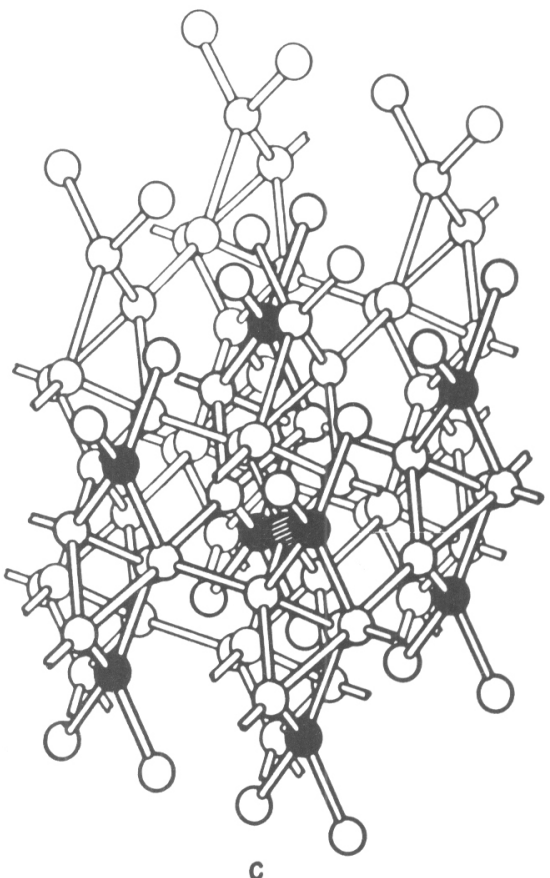

Fig. 11. The structure of ice VI. In column $A$ the hydrogen-bond chains running vertically through the structure are shown. The lower one is identical to the upper but turned through a right-angle. The three-dimensional structures formed from these chains are shown in $B$, while in $C$ the two structures shown in $B$ are combined to form the complete structure of ice VI in which the two components interpentetrate. Protons are not shown. (After Kamb, 1965.)
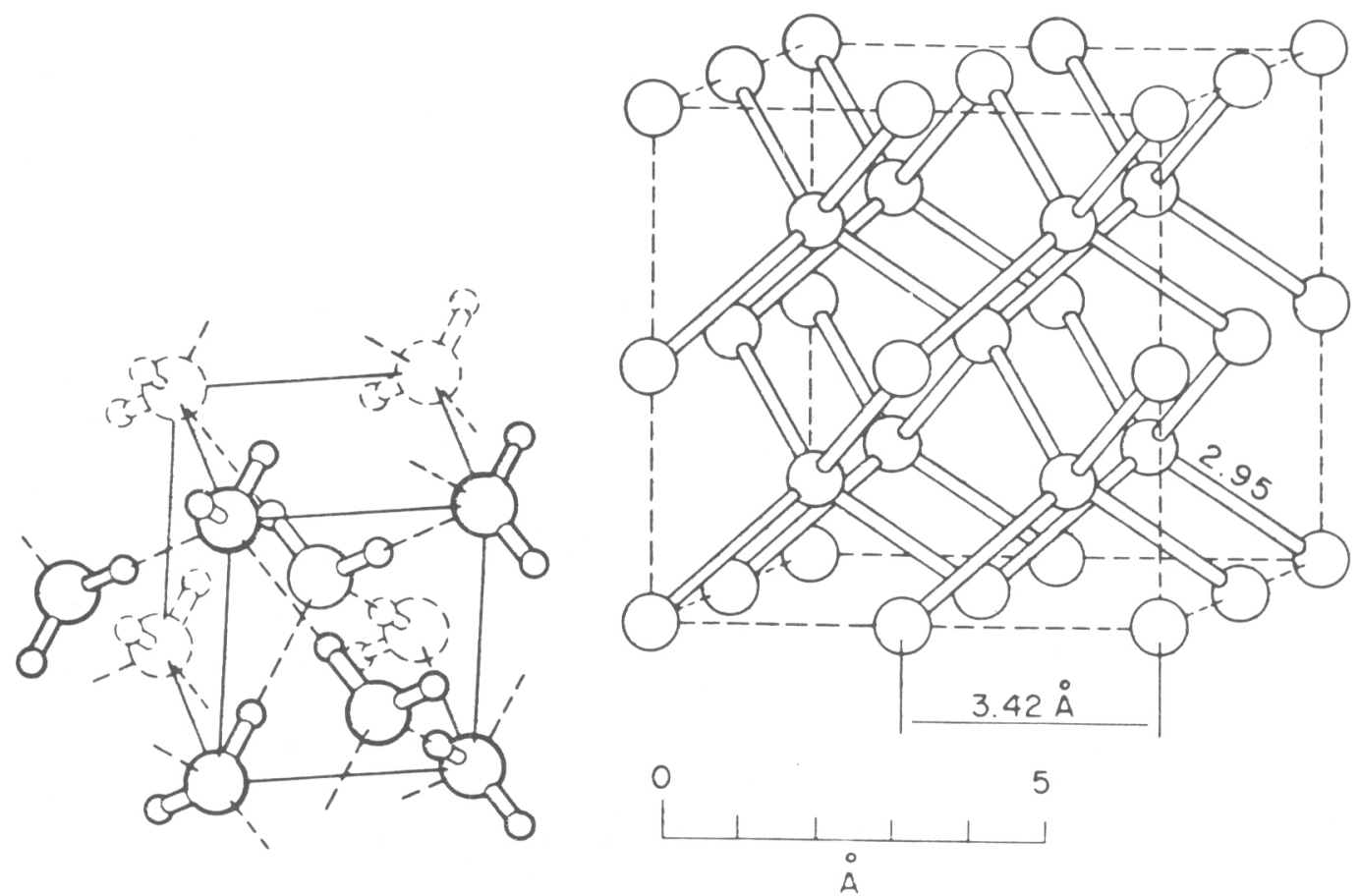

Fig. 12. The structure of ice VII. This is body-centred cubic but hydrogen bonds are limiled to four per oxygen molecule and form two interpenetrating ice Ic structures. The protons are shown disordered. With the protons ordered, the structure would be that of ice VIII. (After Kamb and Davis. 1964.) 
the half century under review. In particular, the development of ice crystals from water vapour has received much attention because of its great importance to meteorologists. Snow crystals have long been seen and admired, but 50 years ago the reasons for the great variety of snowcrystal forms were largely unknown. Nakaya's pioneering experiments on the growth of ice crystals in a controlled environment (artificial snow crystals) were first reported in 1938 and the book summarizing his work was published in 1954 (Nakaya, 1954). These experiments established that both temperature and supersaturation were important in determining the growth habit of snow crystals which varied from needles elongated in the [0001] direction to scrolls, cups, columns, plates, and planar dendrites (Fig. 13). Furthermore, the variation was not monotonic; it appeared

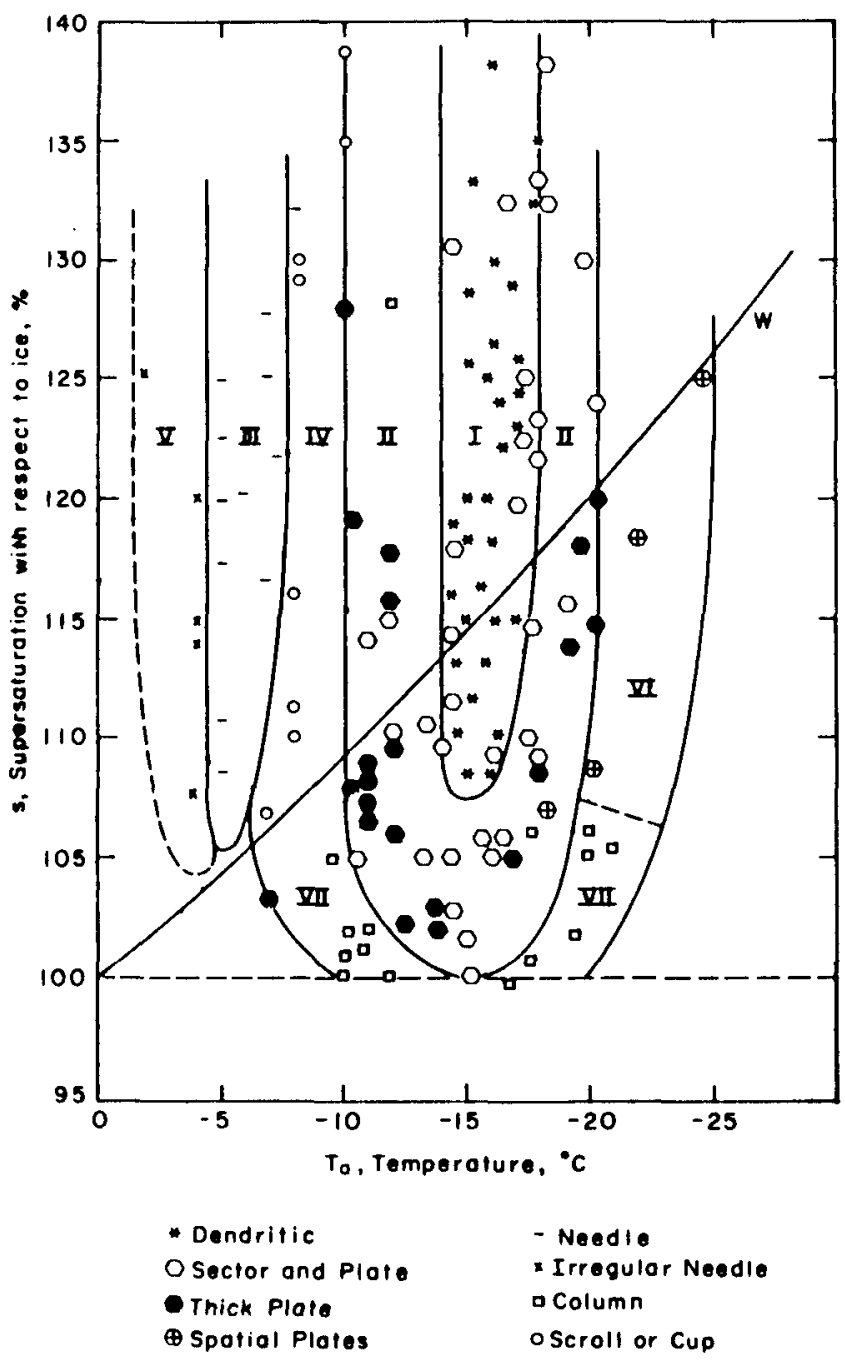

Fig. 13. The various shapes of ice crystals which form under different conditions of temperature and supersaturation. The solid line $W$ marks the limit of supersaturation with respect to liquid water (supercooled). (After Nakaya, 1954.)

to reverse so that, for example, plates appear at both higher and lower temperatures than those appropriate for dendrites. The reason for this rapid change in behaviour has been the subject of many theories throughout the remaining decades.

In addition to the information given by snow-crystal shapes concerning the conditions in the clouds when they were formed, a number of other aspects of ice physics have been much debated by cloud physicists, in particular the possible role of the electrical properties of ice in the generation of thunderstorm electricity. Ice physics has also become of interest to astronomers, both because of the existence of ice particles as constituents of dust in space, and because of the existence of larger ice masses in comets, on planets, and on satellites of planets, some of which may be largely composed of ice. Thus, the interest in the results of ice-physics research has expanded from the original areas of geology and geography to meteorology and astronomy and, increasingly, to engineering problems as increasing developments occur in cold regions.

\section{REFERENCES}

Auty, R.P., and Cole, R.H. 1952. Dielectric properties of ice and solid $\mathrm{D}_{2} \mathrm{O}$. Journal of Chemical Physics, Vol. 20, No. 8 , p. 1309-14.

Auvert, G., and Kahane, A. 1973. Discussion [of paper by J.G. Paren on The electrical behaviour of polar glaciers]. (In Whalley, E., and others, eds. Physics and chemistry of ice: papers presented at the Symposium on the Physics and Chemistry of Ice, held in Ottawa, Canada, 14-18 August 1972. Edited by E. Whalley, S.J. Jones, and L.W. Gold. Ottawa, Royal Society of Canada, p. 271.)

Bernal, J.D., and Fowler, R.H. 1933. A theory of water and ionic solution, with particular reference to hydrogen and hydroxyl ions. Journal of Chemical Physics, Vol. 1, No. 8, p. $515-48$.

Bjerrum, N. 1951. Structure and properties of ice. Det Kongelige Danske Videnskabernes Selskab. Matematisk-fysiske Meddelelser, Bd. 27, Nr. 1.

Bragg, W.H. 1921. The crystal structure of ice. Proceedings of the Physical Society, Vol. 34, Pt. 3, p. 98-102.

Bridgman, P.W. 1935. The pressure-volume-temperature relations of the liquid, and the phase diagram of heavy water. Journal of Chemical Physics, Vol. 3, No. 10, p. 597-605.

Bridgman, P.W. 1937. The phase diagram of water to 45,000 $\mathrm{kg} / \mathrm{cm}^{2}$. Journal of Chemical Physics, Vol. 5 , No. 12, $\mathrm{p}$. 964-66.

Dennison, D.M. 1921. Crystal structure of ice from its X-ray pattern. Physical Review, Ser. 2, Vol. 17, No. 1, p. 20-22.

El-Sayad, M.A., ed. 1983. [Papers presented at the] Sixth International Symposium on the Physics and Chemistry of Ice, University of Missouri-Rolla, August 2-6, 1982. Journal of Physical Chemistry, Vol. 87, No. 21, p. 1A-10A, 4015-340.

Engelhardt, H., and Kamb, W.B. 1978. X-ray determination of the structure of ice IV. Journal of Glaciology, Vol. 21 , No. 85 , p. $51-53$.

Engelhardt, H., and Riehl, N. 1965. Space-charge limited proton currents in ice. Physics Letters, Vol. 14, No. 1, p. 20-21.

Engelhardt, H., and Riehl, N. 1966. Zur protonischen Leitfähigkeit von Eis-Einkristallen bei tiefen Temperaturen und hohen Feldstärken. Physik der Kondensierten Materie, Bd. 5, Ht. 2, p. 73-82.

Fukuda, A., and Higashi, A. 1969. X-ray diffraction topographic studies of the deformation behaviour of ice single crystals. (In Riehl, N., and others, eds. Physics of ice: proceedings of the International Symposium on Physics of Ice, Munich, Germany, September 9-14, 1968. Edited by $N$. Riehl, B. Bullemer, and $H$. Engelhardt. New York, Plenum Press, p. 239-50.)

Fukuda, A., and Higashi, A. 1973. Dynamical behavior of dislocations in ice crystals. Crystal Lattice Defects, Vol. 4, No. 3 , p. 203-10.

Glen, J.W. 1955. The creep of polycrystalline ice. Proceedings of the Royal Society of London, Ser. A, Vol. 228, No. 1175, p. 519-38.

Glen, J.W. 1968. The effect of hydrogen disorder on dislocation movement and plastic deformation of ice. Physik der Kondensierten Materie, Bd. 7, Ht. 1, p. 43-51.

Glen, J.W., and Perutz, M.F. 1954. The growth and deformation of ice crystals. Journal of Glaciology, Vol. 2, No. 16, p. 397-403.

Glen, J.W., and others, eds. 1978. [Papers presented at the] Symposium on the Physics and Chemistry of Ice. Edited by J.W. Glen, R.J. Adie, D.M. Johnson, D.R. Homer, and A.D. Macqueen. Journal of Glaciology, Vol. 21 , No. 85. 
Hamilton, W.C., and others. 1969. Deuteron arrangements in high pressure forms of ice, by W.C. Hamilton, [W.]B. Kamb, S.J. LaPlaca, and A. Prakash. (In Riehl, N., and others, eds. Physics of ice: proceedings of the International Symposium on Physics of Ice, Munich. Germany, September 9-14, 1968. Edited by N. Riehl, B. Bullemer, and $H$. Engelhardt. New York, Plenum Press, p. 44-58.)

Hayes, C.E., and Webb, W.W. 1965. Dislocations in ice. Science, Vol. 147, No. 3653, p. 44-45.

Hirsch, K.R., and Holzapfel, W.B. 1986. Effect of high pressure on the Raman spectra of ice VIII and evidence for ice X. Journal of Chemical Physics, Vol. 84, No. 5, p. $2771-75$.

Hubmann, M. 1979. Polarization processes in the ice lattice. Zeitschrift für Physik B, Bd. 32, Ht. 2, p. 127-46.

Humbel, F., and others. 1953. Anisotropie der Dielektrizitätskonstante des Eises, by F. Humbel, F. Jona, and P. Scherrer. Helvetica Physica Acta, Vol. 26, Fasc. 1, p. 17-32.

Jaccard, C. 1959. Étude théorique et expérimentale des propriétés électriques de la glace. Helvetica Physica Acta, Vol. 32, Fasc. 2, p. 89-128.

Jaccard, C. 1964. Physics of irreversible processes applied to ice. Physik der Kondensierten Materie, Bd. 3, Ht. 2, p. 99-118.

Jones, S.J., and Glen, J.W, 1969. The mechanical properties of single crystals of pure ice. Journal of Glaciology, Vol. 8, No. 54 , p. 463-73.

Kahane, A, 1969. Experimental and theoretical studies on the dc conductivity of ice. (In Riehl, N., and others, eds. Physics of ice: proceedings of the International Symposium on Physics of Ice, Munich, Germany, September 9-14, 1968. Edited by N. Riehl, B. Bullemer, and $H$. Engelhardt. New York, Plenum Press, p. 443-49.)

Kamb, W.B. 1964. Ice II: a proton-ordered form of ice. Acta Crystallographica, Vol. 17, Pt. 2, p. 1437-49.

Kamb, W.B. 1965. Structure of ice VI. Science, Vol. 150, No. 3693, p. 205-09.

Kamb, W.B., and Datta, S.K. 1960. Crystal structures of the high-pressure forms of ice: ice III. Nature, Vol. 187, No. 4732 , p. $140-41$

Kamb, W.B., and Davis, B.L. 1964. Ice VII, the densest form of ice. Proceedings of the National Academy of Sciences, Vol. 52, No. 6, p. 1433-39.

Kamb, W.B., and others. 1967. Structure of ice V, by W.B. Kamb, A. Prakash, and C. Knobler. Acta Crystallographica, Vol. 22, Pt. 5, p. 706-15.

König, H. 1943. Eine kubische Eismodifikation.
Zeitschrift für Kristallographie, Bd. 105, Ht. 4, p. 279-86.

Lile, R.C. 1978. The effect of anisotropy on the creep of polycrystalline ice. Journal of Glaciology, Vol. 21, No. 85, p. $475-83$.

Maï, C. 1976. Etude par topographie X du comportement dynamique des dislocations dans la glace Ih. Comptes Rendus Hebdomadaires des Séances de l'Académie des Sciences (Paris), Sér. B, Tom. 282, No. 22, p. 515-18.

Mellor, M., and Testa, R. 1969. Creep of ice under low stress. Journal of Glaciology, Vol. 8, No. 52, p. 147-52.

Nakaya, U. 1954. Snow crystals natural and artificial. Cambridge, MA, Harvard University Press.

Oura, H., ed. 1967. Physics of snow and ice: International Conference on Low Temperature Science ... August 14-19, 1966, Sapporo, Japan. Proceedings, Vol. 1. [Sapporo], Hokkaido University. Institute of Low Temperature Science.

Pauling, L. 1935. The structure and entropy of ice and of other crystals with some randomness of atomic arrangement. Journal of the American Chemical Society, Vol. 57, No. 12, p. 2680-84.

Petrenko, V.F., and others. 1983. Effects of proton injection on the electrical properties of ice, by V.F. Petrenko, R.W. Whitworth, and J.W. Glen. Philosophical Magazine B, Vol. 47, No. 3, p. 259-78.

Riehl, N., and others, eds. 1969. Physics of ice: proceedings of the International Symposium on Physics of Ice, Munich Germany, September 9-14, 1968. Edited by N. Riehl, B. Bullemer, and $H$. Engelhardt. New York, Plenum Press.

Tammann, G. 1900. Über die Grenzen des festes Zustandes IV. Annalen der Physik, Vierte Folge, Bd. 2, Ht. 5, p. $1-31$.

Whalley, E, and others. 1968. Ice IX: an anti-ferroelectric phase related to ice III, by E. Whalley, J.B.R. Heath, and D.W. Davidson. Journal of Chemical Physics, Vol. 48, No. 5, p. 2362-70.

Whalley, E., and others. 1973. Physics and chemistry of ice: papers presented at the Symposium on the Physics and Chemistry of Ice, held in Ottawa, Canada, 14-18 August 1972. Edited by E. Whalley, S.J. Jones, and L.W. Gold. Ottawa, Royal Society of Canada.

Whitworth, R.W. 1978. The core structure and the mobility of dislocations in ice. Journal of Glaciology, Vol, 21, No. 85, p. $341-59$.

Whitworth, R.W. 1983. Velocity of dislocations in ice on $\{0001\}$ and $\{10 \overline{1} 0\}$ planes. Journal of Physical Chemistry, Vol. 87 , No. 21 , p. 4074-78. 